Las intervenciones de los técnicos remarcaron la idea de la importancia de que el Planeamiento Especial se adapte a los problemas reales y aporte soluciones concretas, que sea asequible y entendible para los ciudadanos y que además de su papel normativo sea un instrumento propositivo.

Con la intervención del Alcalde de la ciudad de Cuenca (Patrimonio de la Humanidad), quedó claro que para un Ayuntamiento la responsabilidad de sacar adelante su ciudad histórica es una empresa ingente frente a la que se encuentra con escasísimos recursos y una buena dosis de incomprensión por parte de sus propios ciudadanos, ante cualquier restricción o limitación acorde con las condiciones que una estructura histórica necesita.

Las declaratorias de Patrimonio de la Humanidad son un recurso excelente para elevar la moral y la autoestima de los ciudadanos, pero lejos de falsas expectativas de ayudas externas, lo cierto es que tienen que ser ellos, con su Ayuntamiento a la cabeza, los que saquen adelante su ciudad histórica.
Como idea final de las jornadas, quedó de manifiesto que en la medida que los ciudadanos necesiten y reivindiquen su Patrimonio, tanto las Administraciones como los técnicos responsables se verán en la obligación de encontrar soluciones a sus problemas y adaptarse a sus demandas, de ahí la importancia de difundir y promover el conocimiento de su realidad.

Fundación de Casas Históricas y Singulares

\title{
Diez años después, los arqueólogos extremeños se reúnen en Mérida
}

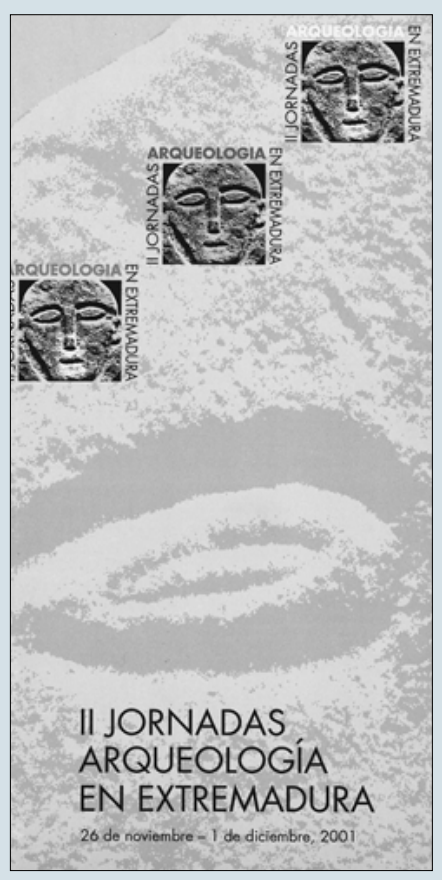

Durante los días 26 de noviembre a I de diciembre de 2001 tuvieron lugar en Mérida las Il Jornadas de Arqueología en Extremadura, a las que asistieron todos los arqueólogos que han trabajado en la Comunidad Autónoma durante los últimos 10 años.

Las jornadas, inauguradas por el Excmo. Sr. Consejero de Cultura, contaron, además con la participación de importantes personalidades de la arqueología española como los Dres. Almagro-Gorbea y Bendala, que se encargaron de pronunciar las conferencias de apertura y clausura.

A lo largo de 4 días se expusieron los resultados de las intervenciones arqueológicas de- sarrolladas en Extremadura en la última década, agrupadas en cuatro secciones: Proyectos Integrales, Actividad Sistemática, Arqueología Urbana y Gestión de la arqueología extremeña. En estas dos últimas fueron especialmente importantes las mesas redondas y debates, en los que se pusieron de manifiesto los problemas de la arqueología regional y las posibilidades y retos para el futuro.

Además, una sección de pósters permitió exponer los resultados de intervenciones de urgencia, u otros pormenores de la investigación científica.

Las jornadas contaron con una importante asistencia, próxima a las 300 personas, destacando el público universitario que fue especialmente participativo. Algunos de los ponentes, miembros del Comité Científico y participantes procedían de Portugal, y también hubo una importante presencia de estudiantes de otras comunidades autónomas, particularmente de Andalucía.

Las sesiones de trabajo se completaron con visitas a los yacimientos más representativos de la Comunidad Autónoma, como los monumentos de la ciudad de Mérida, el palaciosantuario de Cancho Roano (Zalamea de la Serena, Badajoz), la iglesia mozárabe de Santa Lucía del Trampal (Alcuéscar, Cáceres) o el centro de interpretación de la Cueva de Maltravieso (Cáceres).

Durante el acto de clausura se entregó a los asistentes un ejemplar del libro "ABAE", (Archivo Bibliográfico de Arqueología Extremeña), una completa recopilación con más de 3500 fichas bibliográficas comentadas sobre arqueología extremeña, desde el siglo XVI hasta el año 2000, que constituye el número IX de la serie Extremadura Arqueológica.

En la cena de clausura se homenajeó a D. Batolomé Gil Santacruz, empresario extremeño que ha contribuido al estudio y conservación del Patrimonio Arqueológico regional con el mecenzago de varias obras y proyectos, como el de Cancho Roano.

Una comparación con las I Jornadas celebradas en Cáceres en 1990 permite comprobar la evolución experimentada por la arqueología extremeña de finales del siglo $X X$, a través del desarrollo de proyectos vertebradores del territorio que incluyen la proyección social como uno de sus objetivos fundamentales, y mediante la incorporación de un creciente número de profesionales a la población activa de la región, tanto en el sector público como en el privado. Sensibilizar a los diferentes colectivos sociales de la importancia del Patrimonio Arqueológico, desarrollar y aplicar la legislación en esta materia y proteger unos bienes no renovables en una sociedad en pleno desarrollo, son los retos del futuro.

La organización de las Jornadas corrió a cargo de la Consejería de Cultura junto con el Consejo Superior de Investigaciones Científicas y la Universidad de Extremadura, y contó con la colaboración de la Asamblea, las diputaciones provinciales y el Ayuntamiento de Mérida.

Está prevista la publicación de las actas con los contenidos de las contribuciones en la serie Extremadura Arqueológica.

Javier Jiménez Ávila 